\title{
The Present Situation and the Improvement Measures of Intellectual Property Protection of Traditional Chinese Medicine in China Jin-guo WANG ${ }^{1, \mathrm{a}}$ and $\mathrm{Na}_{\text {WANG }}{ }^{2, \mathrm{~b},{ }^{*}}$ \\ ${ }^{1}$ Department of Urology, the First Hospital of Jilin University, China \\ ${ }^{2}$ Department of Anesthesiology, the First Hospital of Jilin University, China \\ awangjinguolily@163.com, bwangna080613@163.com \\ ${ }^{*}$ Corresponding author
}

Keywords: Chinese medicine, Intellectual property, Protection, Tradition.

\begin{abstract}
The current intellectual property system in our country has many defects in the protection of traditional Chinese medicine, so it causes expensive loss of intellectual property of traditional Chinese medicine. In addition, the absent understanding of the importance of intellectual property rights protection makes the situation worse. On the base of previous research, we suggest to carry out patent protection, brand protection, business secret protection and copyright protection to improve the current intellectual property system to protect intellectual property of traditional Chinese medicine in our country.
\end{abstract}

\section{Introduction}

Made great contribution to Chinese traditional medicine for our country's national health, and has set up a move towards the world, however, doesn't get prosperity of traditional Chinese medicine industry in our country. Appear this kind of phenomenon, and implementation in our country and traditional Chinese medicine culture is not suitable to patent, trademark, trade secrets, geographical indications and other western creation of protection of intellectual property rights system about Chinese medicine, China's property protection existence question, and the lack of traditional Chinese medicine culture innovation motivation mechanism independently work out international law system of traditional Chinese medicine [1]. Therefore, in order to effectively protect the traditional culture, Chinese medicine must establish protection system suitable to China's traditional Chinese medicine culture characteristics and innovation incentive mechanism.

\section{The Concept of the Traditional Chinese Medicine}

\section{The Traditional Medicine Only Takes Patients As Carriers of Diseases.}

Chinese medicine is Chinese traditional medicine, Chinese medicine involves products include Chinese herbal medicine, Chinese medicine, proprietary Chinese medicine, extracts, health care products and cosmetics containing Chinese native medicine ingredient, the traditional Chinese medicine is the main raw material of medicinal plants. The international pharmaceutical industry is a trend of returning to nature, the increasing demand for natural medicines, increasing emphasis on the natural drugs. Japan has already begun investing heavily study of traditional Chinese medicine (TCM), 
the government clearly that Chinese medicine should be brought into the medical insurance [2].

\section{Two Problems Existing in the Protection of Traditional Chinese Medicine}

Government and enterprises in China on the protection of the traditional culture of Chinese traditional medicine does into certain financial and material resources and manpower, but the protection of the traditional culture of traditional Chinese medicine (TCM) still exist many unsolved problems, overall because always has the following defects, so that the corresponding issue has not been found and solved.

\section{The Existing Intellectual Property System is not Suitable for Protection of Traditional Chinese Medicine Culture}

Current intellectual property system is essentially the western developed countries to protect its advanced technology and design a system, not suitable for protection with more than many years civilization of Chinese traditional medicine culture. China's traditional knowledge of Chinese medicine literature degree is quite high, does not have novelty required by the patent protection system, resulting in traditional Chinese medicine can't get comprehensive and reasonable from the perspective of patent protection [3]. So there is the commercial secret makes Chinese traditional medicine can not be effectively promote, not well play the social value of Chinese traditional medicine, also cannot fully realize its economic value. Geographical indication is can be applied to some traditional Chinese medicine, but it may not apply to all, and even may not apply to most.

\section{Improving the Legal System of the Traditional Culture of Chinese Medicine}

Protection of TCM variety regulation is creative legal protection of traditional Chinese medicine in China traditional culture, but it is just a administrative rules and regulations, and legal status is not high, and applies only to the domestic production of varieties of traditional Chinese medicines and included in the national drug standards, is not in conformity with the principle of national treatment. And trademark protection is conducted on the name of the protection, even if the enterprise do their best to reach to the top, also can only is their products more popularity, does not exclude the production and sale of others, not for the physical and chemical medicine production technology to provide protection [4]. Commercial secrets to reverse deciphered brought out by the science and technology development and frequent exchanges, in the tide of globalization to protect the traditional Chinese medicine culture has overwhelmed.

\section{Lack of Incentive Mechanism of Traditional Chinese Medicine Innovation}

As the sole survivor of four big ancient traditional medicine of traditional Chinese medicine. Present, referring to the traditional culture of Chinese medicine, people is more thought of seeking cure way from the viewpoints of ancient books, forget the traditional Chinese medicine culture only continuous innovation, in accordance with the time development to better treatment of traditional disease, to better deal with new diseases [5].

\section{Lack of International Law System of Traditional Chinese Medicines}

Now although there are some studies on the international protection of the traditional Chinese medicine, but mainly from traditional Chinese medicine to the international market, how to adapt to the market and how to protect themselves in the market, are 
some measures for the protection of defensive, belongs to a kind of passive study. In terms of its essence, we how to adapt to the rules of other countries, how to use rules of other countries to protect themselves, there is almost no participation, even in China are put forward leading international rules related to the protection of traditional Chinese medicine culture.

\section{The Improvement Measures of Traditional Chinese Medicine Culture Protection}

The Chinese government has tried to build system of intellectual property rights, but until the founding of new China, the legal system did not play a proper role. Really comprehensive intellectual property system in China, it is after the reform and opening up. At present, the traditional Chinese medicine because of the intellectual property rights is mainly through the patent right, trademark right, commercial secret, geographical indications and other legal system to protect.

\section{The Protection Mode of Patent}

The preparation method of the implementation of the patent law in our country is only on drug patent, so not many traditional Chinese medicine patent filings. And these patents are mainly focused on creative lower dosage form of traditional Chinese medicine formula and change two types of patent. At present our country patent more focused on a limited number of high quality foreign companies, but foreign companies patent technology is mainly used for chewing gum market high profits [6]. On the international patent, traditional Chinese medicine is faced with the problem is more serious, so that there is no corresponding classification position. In the international patent classification, such as traditional Chinese medicine drugs because the material is not clear, the effect is not clear, there is no specific classification, and other natural plant medicine, most were classified as containing raw materials or with unknown structure of the reaction product of medical products.

\section{Brand Protection}

General indifference of traditional Chinese medicine industry in our country, trademark consciousness, outstanding performance is due to a lack of awareness of registered trademark was registered in foreign countries, and improper use of trademark and trademark renew expired not note, etc. Chinese medicine enterprises are less attaches great importance to the design and using of trademark, led to the consumer is familiar with the common name of the drug, and the trademark is rather neglected, such as everyone is familiar with pills and other medicines common name, but don't know which brand of product quality is more reliable [7]. This kind of circumstance also exist in medicinal herbs planting, growers put up improve their quality and yield, but I don't know to use trademark raise public awareness of medicinal materials, seriously affect the price of medicine and plant efficiency.

\section{The Protection of Business Secrets}

Business secret is not for the public, can bring economic benefits to the oblige to known, practical and security measures shall be taken by the holder of the technical information and business information. If not a recipe for patent application, new drug formulation, processing methods, preparation technology, the proportion of compatibility of compound Chinese herbal medicine cultivation technology, etc. USES the business secret protection way is way, the protection of traditional Chinese medicine (TCM) in 
the history of the development of Chinese traditional medicine recipe, with a large number of dense heralded preach man not even within the family as a female [8].

\section{The Protection of Geographical Indications}

Definition of a geographical indication is to identify the goods from or the territory of a member within the territory of a regional or local tag, specific quality, reputation or other characteristics of the goods mainly attributable to its geographical origin. And "geographical origin" should include natural factors.

\section{Summary}

Cultural factors, natural factors including climate, soil, etc., human factors including producers in a particular geographic area formed special professional tradition, etc. Visible, geographical indication is also a way to protect the authentic Chinese herbal medicine.

\section{References}

[1] Stephen Cotgrove. Technology, Rationality and Domination. Social Studies of Science. 1975

[2] Walter L. Wallace. Rationality, Human Nature, and Society in Weber's Theory. Theory and Society. 1990

[3] Rachel Laudan. Natural Alliance or Forced Marriage? Changing Relations between the Histories of Science and Technology. Technology and Culture. 1995

[4] Schmickel. D. The Biotechnology Industry Organization's View on Hatch-Waxman Reform. Food and Drug Law Journal. 1999

[5] Abboud L, Burton T.M. Patent Challenge Could Endanger Lilly‘s Zyprexa. The Wall Street Journal. 2004

[6] A. Lincoln. The Second Lecture on Discoveries and Inventions. The Collected Works of Abraham Lincoln. 1953

[7] Stephan Fuchs. The Social Organization of Scientific Knowledge. Sociological Theory. 1986

[8] Gili S. Drori. The Relationship between Science, Technology and the Economy in Lesser Developed Countries. Social Studies of Science. 1993. 